\title{
Release of the Pro-Inflammatory Markers by BEAS-2B Cells Following In Vitro Exposure to Biodiesel Extracts
}

\author{
Kimberly J. Swanson ${ }^{1, \#}$, Norman Y. Kado ${ }^{2}$, William E. Funk ${ }^{1}$, Joachim D. Pleil ${ }^{3}$, \\ Michael C. Madden ${ }^{4, *}$ and Andrew J. Ghio ${ }^{4}$
}

\begin{abstract}
${ }^{I}$ Department of Environmental Sciences \& Engineering, The School of Public Health, University of North Carolina, Chapel Hill 27514; ${ }^{2}$ Department of Environmental Toxicology, University of California, Davis 95616 and California Air Resources Board, Sacramento, CA. 95812; ${ }^{3}$ The National Exposure Research Laboratory and ${ }^{4}$ The National Health and Environmental Effects Research Laboratory, U.S. Environmental Protection Agency, Research Triangle Park, NC 27711, USA and ${ }^{\sharp}$ Currently at Perrin Quarles Associates, Charlottesville, VA 22911, USA
\end{abstract}

\begin{abstract}
Biodiesel, an alkyl ester of plant oils that can be used in an unmodified diesel engine, is the first renewable diesel fuel alternative to become a commercially accepted part of our nation's energy infrastructure. For traditional diesel fuel exhaust, it has been demonstrated that the particulate matter (PM) organic components play a role in acute inflammatory reactions. However, there have been only a few cytotoxicity and mutagenicity studies on biodiesel emissions. In this study, BEAS-2B cells, a transformed human airway epithelial cell line, were exposed in vitro to the PM organic extracts from Standard Reference Material (SRM) 1975, soy ethyl ester (SEE), soy methyl ester (SME), and petroleum diesel for 24 hours. This study demonstrated that the organic extracts of biodiesel PM in an aqueous solution can increase the release of pro-inflammatory cytokines IL- 8 and IL- 6 by respiratory epithelial cells. On a microgram PM equivalent per ml ( $\mu \mathrm{g}$ PM eq/ml) basis, exposure to biodiesel extracts was associated with a greater release of IL- 8 and IL-6 relative to organic extracts of two diesel PM samples. The dose range tested was not cytotoxic. It was also noted that the solvent exchange method, which was used to prepare the aqueous exposure doses, may not be appropriate for the investigation of biodiesel extracts, though it has been used extensively in petroleum diesel research. A valuable new finding from these experiments is that the soluble organic fraction (SOF) of biodiesel PM begins to elicit a cytokine response in BEAS-2B cells at an exposure lower than petroleum diesel PM extract (approximately $40 \mu \mathrm{g} \mathrm{PM} \mathrm{eq/ml).} \mathrm{However,} \mathrm{more} \mathrm{research} \mathrm{is}$ required to better characterize the potency of the organic fraction of biodiesel compared to petroleum diesel.
\end{abstract}

Key Words: Air pollution, vehicle emissions, diesel fuels, diesel exhaust, biodiesel, lung diseases, pro-inflammatory cytokines, IL-8, IL-6.

\section{INTRODUCTION}

The Clean Air Act (CAA) as amended in 1990 requires the United States Environmental Protection Agency (US EPA) Administrator to publish a list of pollutants that have adverse effects on public health or welfare, and are emitted from numerous and diverse stationary or mobile sources [1]. There are six regulated air pollutants referred to as "criteria pollutants": carbon monoxide $(\mathrm{CO})$, nitrogen oxides $\left(\mathrm{NO}_{\mathrm{x}}\right)$, sulfur dioxide $\left(\mathrm{SO}_{2}\right)$, particulate matter (both $\mathrm{PM}_{10}$ and $\left.\mathrm{PM}_{2.5}\right)$, ozone $\left(\mathrm{O}_{3}\right)$, and lead $(\mathrm{Pb})$. National Ambient Air Quality Standards (NAAQS) are set for each pollutant at levels that, based on certain criteria, are intended to protect the public health and the public welfare from any known or anticipated adverse effects [2].

As motorized transportation grew, vehicle emissions, considered a mobile source by the CAA, became a significant source of air pollutants. The 2000 US EPA report on

*Address correspondence to this author at the MD\# 58B, Human Studies Division, NHEERL, US EPA, Research Triangle Park, North Carolina 27711, USA; Tel: (919) 966-6257; Fax: (919) 966-6367;

E-mail: madden.michael@epa.gov
National Air Pollutant Emission Trends [2] contains the latest (1998) source apportionment data and reveals that gasoline and diesel emissions from On-Road Vehicle and NonRoad Engines and Vehicles were the biggest contributors of $\mathrm{CO}(79 \%), \mathrm{NO}_{\mathrm{x}}(53 \%)$, and VOCs $(43 \%)$ and the second most important contributors of both $\mathrm{PM}_{10}$ and $\mathrm{PM}_{2.5}(19 \%$ and $21 \%$, respectively). Diesel combustion is the biggest contributor of $\mathrm{NO}_{\mathrm{x}}$ emissions in the source categories $\mathrm{On}$ Road Vehicle and Non-Road Engines and Vehicles [2]. The US EPA has also been engaged in research related to diesel and other source air pollutants for several decades. As a result of this investigation, petroleum diesel exhaust today is recognized to cause a tissue-specific and systemic inflammation, cardiopulmonary injury, and aggravate allergic disease.

Biodiesel is the first renewable diesel fuel to show signs of becoming a commercially accepted part of our nation's energy infrastructure. Biodiesel combustion will be a new emission source. There have been limited cytotoxicity and mutagenicity studies on biodiesel exhaust in biological systems. In an Ames bacterial assay, biodiesel exhaust PM extracts were generally more mutagenic than extracts of petroleum diesel exhaust PM on an equal mass basis, but not on 
PM mass emitted per work unit per hour. The exhaust emissions of biodiesel prepared from the more common plant-oil feedstocks (i.e. soybean and rapeseed oil) have been extensively physicochemically characterized under field and laboratory conditions [3-10]. Biodiesel exhaust has been shown to contain less PM, CO, polycyclic aromatic hydrocarbons (PAH), and no sulfur compared to petroleum based diesel exhaust $[6,9,11,12]$. However, compared to diesel fuel, the combustion of biodiesel in a diesel engine may increase $\mathrm{NO}_{\mathrm{x}}$ emission, which, in addition to inducing potential health effects itself, has been identified as an ozone precursor [6, 7]. Biodiesel may "burn cleaner" than petroleum diesel but the true biological impact of biodiesel exhaust PM extracts, also known as soluble organic fraction (SOF), upon respiratory epithelial cells or other lung cell types and in vivo has not been investigated extensively. Only very recently one type of biodiesel exhaust PM extract was shown to induce less apoptosis compared to petroleum diesel PM extract in the lung cell line A549 [6, 7]. It is unclear whether and to what degree biodiesel exhaust exposure can induce human lung inflammation, and uncertainty exists about the relative potency compared to lung inflammation (evidenced by neutrophilia and IL- 8 and IL-6 increases) [13] induced by acute exposure to petroleum diesel exhaust. We therefore exposed bronchial epithelial cells to biodiesel extract and measured indices reflecting viability and cytokine mediators of the human lung inflammatory response.

\section{MATERIAL AND METHODS}

\section{Cell Culture Conditions}

The immortalized human bronchial epithelial cell line, BEAS-2B, was kindly provided by Drs. Curtis Harris and John Lechner of the National Institute of Health, USA. The cells were cultured using the keratinocyte growth media (KGM) with serum-free composition as previously described [14] (Lonza Walkersville, Inc. Cells (passages 66-74) were grown on tissue culture treated 96-well plates (Costar, Cambridge, MA) at $\sim 2 \times 10^{4}$ cells/well. At the time of exposure, wells were checked microscopically for confluence and wells approaching $\sim 100 \%$ confluence were used.

\section{Biodiesel Samples: Collection, Extraction, and Procure- ment}

The engine utilized to generate diesel exhaust was a 1997 Caterpillar $3406 \mathrm{E}$ heavy-duty in line six cylinder, four stroke, turbocharged, aftercooled 14.6 L engine. The EPA Heavy-Duty Diesel Engine Transient Test Cycle (CFR40, Pt.86, Subpt.N) was used; this cycle incorporates a city and highway driving component. PM was collected on $90 \mathrm{~mm}$ Teflon-coated glass-fiber filters (T60A20, Gelman SciencesPallflex, Ann Arbor, MI), which were pre-cleaned with dichloromethane (DCM) and methanol. Filters were extracted in the DCM as described [15]. Generally biodiesel exhaust PM size is emitted as $<1 \mu \mathrm{m}$, but collection on filters will increase the particle size. Further detailed information regarding fuel composition, testing protocol, and engine emissions are described in $[6,15]$. DCM has been reported to extract the largest quantity of biologically active material from particulate matter, and is usually the solvent of choice chosen for biological screening [16].

The test fuel properties and the regulated emissions for the samples are summarized (Table 1). Samples tested in the in vitro system included PM extracts of soy ethyl ester (SEE), soy methyl ester (SME provided by C. Peterson at the University of Idaho), Phillips No. 2 diesel (D2), a tunnel background sample, a solvent blank (DCM), and Standard Reference Material (SRM) 1975. The code for the samples was not revealed until the study was completed. The tunnel blank extract was assigned a mass concentration similar to other samples so as to prevent researchers from suspecting the extract was a blank. The tunnel blank filter was collected by pulling an equivalent volume of dilutional air as in diesel

Table 1. Test Fuel Properties and Regulated Pollutant Emissions for the Samples. Included are Currently Accepted Fuel Property Standards and the EPA Emission Standard for the 1994 Heavy-Duty Engine Model Year

\begin{tabular}{|c|c|c|c|c|}
\hline & $\begin{array}{l}\text { Hydrogenated Soy } \\
\text { Ethyl Ester (SEE) }\end{array}$ & $\begin{array}{l}\text { Soy Methyl } \\
\text { Ester (SME) }\end{array}$ & $\begin{array}{l}\text { Philips No. } 2 \\
\text { Diesel (D2) }\end{array}$ & Currently Accepted Standard \\
\hline Specific gravity, $60 / 60$ & 0.873 & 0.886 & 0.849 & - \\
\hline Sulfur $(\%$ wt $)$ & $<0.005$ & 0.012 & 0.036 & $0.05 \max$ \\
\hline \multirow[t]{2}{*}{ Iodine number } & 71.7 & 97.4 & 8.6 & $115 \max$ \\
\hline & \multicolumn{3}{|c|}{ Regulated Pollutant Emissions (ave, g/bhp-h) } & $\begin{array}{l}\text { EPA Emission Standard for } 1994 \text { Heavy } \\
\text { - Duty Engine Model Year (g/bhp-h) }\end{array}$ \\
\hline NOx & 4.775 & 5.33 & 4.55 & 5 \\
\hline $\mathrm{PM}$ & 0.03833 & 0.04 & 0.077 & 0.1 \\
\hline
\end{tabular}


exhaust runs. The solvent blank (control) sample, though lacking measurable mass, was diluted in the same manner as samples diluted to 10,25 and $40 \mu \mathrm{g}$ PM eq/ml.

Standard Reference Material (SRM) 1975 is a DCM extract of diesel particulate matter collected from an industrial diesel-powered forklift [17]. The particulate matter extracted was SRM 2975 [18] which is a reference material supplied by the National Institute of Standards \& Technology (NIST, Gaithersburg, MD). Since the quantities of the biodiesel extracts were limited, SRM 1975 served as a surrogate extract to develop a method for exposing the cells. SRM 1975 was also included in the cell exposure studies as a diesel PM soluble organic faction (SOF) control. A new ampule of SRM 1975 containing approximately $1.2 \mathrm{ml}$ of a DCM extract of diesel particulate matter was used in each in vitro experiment [17]. The reference value for extract residue mass in SRM 1975 is $19.3 \pm 0.2 \mathrm{mg} / \mathrm{ml}$. This soluble organic fraction (SOF) of SRM 2975 is only $2.7 \%$ of the total particulate matter mass. The SOF of the petroleum and biodiesel samples was not determined.

\section{Aqueous Preparation of Organic Biodiesel and Diesel PM Extracts}

A solvent exchange method, which has been used extensively in petroleum diesel exhaust research [16, 19-21] was used to prepare aqueous solutions of the biodiesel and diesel PM extracts. Each DCM particle extract had a reported concentration ( $\mu \mathrm{g}$ PM eq/ml DCM), which was needed to calculate the stock concentration and the serial dilutions for the exposure doses. The DCM solvent blank and tunnel blank (which was essentially particle free and attributed with zero mass) was treated in the same manner as the other samples in terms of solvent evaporation and reconstitution in vehicle. The exposure concentrations of organic extracts are reported as microgram PM equivalent per $\mathrm{ml}$ of media ( $\mu \mathrm{g} \mathrm{PM}$ eq $/ \mathrm{ml}$ $\mathrm{KGM}+0.2 \%$ DMSO). Working in a $4^{\circ} \mathrm{C}$ cold room to minimize evaporative loss, aliquots of the UCD samples, equivalent to $40 \mu \mathrm{g}$ PM eq/ml, were dispensed into 1.5 microcentrifuge tubes. At room temperature, the DCM was evaporated under a stream of $\mathrm{N}_{2}$. Dimethylsulfoxide (DMSO, Biotech grade, $99.8 \%$, Sigma-Aldrich) was added to the dried residue and then further diluted in KGM. The final concentration of DMSO was $0.2 \%(\mathrm{v} / \mathrm{v})$. The $40 \mu \mathrm{g} P \mathrm{PM}$ eq $/ \mathrm{ml}$ dose of the samples was serially diluted to 25 and $10 \mu \mathrm{g} P M$ eq $/ \mathrm{ml}$ in vehicle (i.e., $0.2 \%$ DMSO in KGM). This concentration of DMSO was chosen in order to optimize dissolution of dried extracts into media as examined by peak height and area in UV/VIS spectroscopy (describe below). Cells incubated in vehicle with $0.2 \%$ DMSO did not have decreased viability; we have reported that the cytotoxicity with DMSO typically does not increase until approximately $3.8 \%$ [22]. It is unclear if $0.2 \%$ DMSO affects other cellular processes relative to $0 \%$ DMSO. SRM 1975 was prepared in a $15 \mathrm{ml}$ conical tube as a stock concentration of approximately $1,845 \mu \mathrm{g}$ PM eq/ml or $50 \mu \mathrm{g} / \mathrm{ml}$ of extractable material (SOF) in $\mathrm{KGM}+0.2 \%$ DMSO. Exposure doses of SRM 1975 were 10, 25, 50, 184, 369,922 , and $1,845 \mu \mathrm{g} \mathrm{PM}$ eq/ml, roughly equivalent to $0.27,0.68,1.35,5,10,25$, and $50 \mu \mathrm{g} / \mathrm{ml}$ of SOF.

Ultraviolet/visible spectroscopy (UV/VIS) was used as a tool to evaluate the solvent exchange process. UV/VIS spectroscopy is a technique to verify that organics extracted into
DCM were in the aqueous preparation of SOF. The spectrophotometer used was a Beckman DU 640 (Beckman Coulter, Inc., Fullerton, CA).

\section{Analysis of Cell Viability}

After $24 \mathrm{~h}$ incubation, cells were inspected at 20x magnification using standard light microscopy techniques and cellular changes due to exposure were noted. Cell viability was determined quantitatively using either lactate dehydrogenase (LDH) activity and/or the MTT Proliferation Assay (American Type Culture Collection, Manassas, VA). LDH activity was measured using the CytoTox 96 Cytotoxicity Assay (Promega, Madison, WI) with detection at $490 \mathrm{~nm}$. The MTT assay uses the tetrazolium salt, MTT (3-(4,5-dimethylthiazolyl-2)-2,5-diphenyltetrazolium bromide) and is a colorimetric assay based on the capacity of mitochondrial enzymes of metabolically active cells to transform the tetrazolium salt into formazan [23]. The accumulated dark blue crystals were then solubilized by an alcohol and absorbance measured at $570 \mathrm{~nm}$. A decrease in optical density (OD) indicates less MTT formazan formation, an indication cells have lost metabolic function, a sign of cell dysfunction. As a positive control for the MTT assay, wells in replicates of 3 were exposed to Triton-X 100 at $25 \mu \mathrm{M}, 50 \mu \mathrm{M}$, and 100 $\mu \mathrm{M}$. The OD measurements were made using the ELx808 Automated Microplate Reader by Bio-Tek Instruments, Inc., (Winooski, VT) interfaced with KCjunior for Windows Data Reduction Software (KCjunior v.1.41.5 by Bio-Tek Instruments, Inc., Winooski, VT) loaded onto a Compaq Pentium 4 computer.

\section{Cytokine Assays}

A dose range was established for both SRM 1975 (10$1,845 \mu \mathrm{g}$ PM eq/ml) and the UCD extracts (10-40 $\mu \mathrm{g}$ PM $\mathrm{eq} / \mathrm{ml}$ ) which was not cytotoxic. Subsequent to defining a concentration which was not toxic, dose-response studies using SRM 1975 and the UCD extracts were conducted, in which BEAS-2B were exposed for 24 hours. The cell supernatants were pipetted into $1.5 \mathrm{ml}$ microcentrifuge tubes and centrifuged for $5 \mathrm{~min}$ at $14,000 \mathrm{rpm}$ in a cold room to remove cellular debris. Cell culture supernatants were stored at $-80^{\circ} \mathrm{C}$ overnight prior to performing the CXCL8/IL-8 and IL6 assays. Commercially available human enzyme-linked immunosorbent assay (ELISA) kits (Quantikine, R \& D Systems, Minneapolis, MN) were used to detect and quantify the pro-inflammatory cytokines in the cell supernatants. The CXCL8/IL-8 and IL-6 assays were performed according to manufacturer's instructions for cell supernatants (CXCL8/ IL-8 Catalog Number D8000C and IL-6 Catalog Number D6050). Detection limits for IL-8 and IL-6 are approximately 31 and $3 \mathrm{pg} / \mathrm{ml}$, respectively. These assays are colorimetric and the optical density $\left(\mathrm{OD}_{450}\right)$ measurements were made using the ELx808 Automated Microplate Reader.

\section{PAH Analyses}

Biodiesel exhaust extracts were dried under $\mathrm{N}_{2}$, and subsequently redissolved in DCM with deuterated PAHs (as internal standards) for injection into a GC/MS. Thirteen PAH species, ranging from 3 to 6 rings, were analyzed using an Agilent Technologies (Palo Alto, CA) system consisting of a $6890 \mathrm{~N}$ GC, 5973N MS, with an autoinjector as de- 
scribed [24]. Limits of PAH detection were approximately 5 pg on line.

\section{Statistical Analyses}

Three separate in vitro experiments were conducted in which all biodiesel samples were tested simultaneously. In the first experiment, each dose was tested in duplicate $(n=2$ wells per treatment). In the subsequent two dose-response experiments each dose was performed in triplicate $(n=3$ wells per treatment). Replicates were averaged so there is one mean value per experiment. Any well where cytotoxicity was established (i.e., percent LDH release > 50\% and/or percent viability $<50 \%$ and visual observation of cell detachment and rounding) was coded as a non-normal functioning cell system and the IL-8 and IL-6 response was excluded from the analysis.

Graphs and statistical analysis were performed in GraphPad Prism version 4.03 (GraphPad Software, Inc., San Diego, CA). For each experiment, the IL-8 and IL-6 response at each exposure dose was plotted for the control (solvent blank), petroleum diesel (D2), SRM 1975, biodiesel (grouped as SEE and SME) and a linear regression equation was fitted for the response in each fuel tested. The $95 \%$ confidence intervals were plotted for the regression line. The relative potency of the PM extracts is the slope of the linear regression equation fitted through the dose-response data. The units for the slope, or the rate of change, were pg of protein/ $\mu \mathrm{g}$ PM eq. [25].

Subsequently, IL-8 and IL-6 raw data comparisons by PM extract type were carried out using the Kruskal-Wallis (one-way ANOVA) nonparametric test, followed by Dunn's Multiple comparison test of differences in rank sums (no dose categories). A nonparametric test was selected because there was not enough data in any one category to perform a parametric ANOVA, a consequence of too little material available to test, and due to a high value in experiment 2. By combining exposure types into three distinct categories [e.g. control group (KGM + 0.2\% DMSO and solvent blank), diesel (SRM 1975 and D2), and biodiesel] and combining all results for each dose category, the data can be ranked and the median response statistically evaluated.

For the experimental controls (e.g. tunnel blank and solvent blank), the average IL- 8 and IL-6 concentrations were analyzed by the Mann-Whitney test, the non-parametric equivalent to the t-test. This test evaluates whether the median IL- 8 or IL-6 responses are statistically different between the tunnel background and the solvent blank. Such analysis is important for validating negative controls which were included during the engine testing and at the time of processing of the SOF materials.

\section{RESULTS}

\section{Organic Chromophores in Aqueous Preparations of Bio- diesel PM Extracts}

UV/VIS spectroscopy (200-800 nm) is a simple qualitative technique to verify that organic chromophores (e.g. aromatics and conjugated aliphatics) are in the aqueous preparation of the SOF of the diesel and biodiesel to which the cells are exposed. The DCM organic extracts are likely a mixture of compounds (i.e. aromatic and aliphatic). Absor- bance peaks will overlap in a solution that contains several organic compounds. The UV/VIS spectrum below approximately $250 \mathrm{~nm}$ is not relevant because the absorbance of DMSO in the KGM dominates.

UV/VIS spectra are shown in Fig. (1) from one representative experiment of the $40 \mu \mathrm{g}$ PM eq/ml dose for SEE (Fig. 1A), SME (Fig. 1B), and petroleum diesel (D2) (Fig. 1C). The profiles are different between SEE and SME suggesting different constituents and/or amounts. The SME profile is more similar to the D2 diesel profile, a finding consistent between experiments. The solvent blank (control), the $50 \mu \mathrm{g}$ PM eq/ml dose of SRM 1975, and the media with DMSO alone are presented in Fig. (1D, 1E, and 1F), respectively. The solvent blank (Fig. 1D) shows no detectable absorption peaks between 260 and $380 \mathrm{~nm}$. Absorbance in the diesel profile and the SRM 1975 profile (Fig. 1E) would suggest organics are present in solution. Different components may be present in each sample but without well resolved absorbance peaks it is difficult to tell if the absorbance profiles differ. The PAH content of the biodiesel exhaust extracts (SEE, SME) and petroleum diesel were at or below the nondetectable limit for the 13 compounds examined when analyzed by GC-MS (data not shown) at the low PM equivalents used in these studies.

\section{Effects of Biodiesel and Diesel Extracts on Cell Viability}

Across all experiments and all samples, no biodiesel sample was consistently cytotoxic at the doses tested. This observation was based on no changes in released LDH activity, MTT metabolism, and the cells remaining attached and morphologically similar under light microscopy. The range used for SRM 1975 also did not reduce cell viability (data not shown).

\section{Cellular Cytokine Response}

The release of IL- 8 and IL-6 cytokines were used as markers of the pro-inflammatory response induced in BEAS2B cells exposed for 24 hours to different fuel emission particle extracts. For each experiment, response data at each dose were plotted for five exposure groups: control (DCM solvent blank), KGM + 0.2\% DMSO, Petroleum Diesel (D2), SRM 1975, and biodiesel (SEE and SME extracts combined). The mean cytokine response ( \pm standard deviation) for $\mathrm{KGM}+0.2 \% \mathrm{DMSO}$, the vehicle control, is plotted at the zero dose in all the figures presented.

Biodiesel, as a category, induced a dose-dependent increase in IL- 8 and IL- 6 release by BEAS-2B cells that was always higher than cells exposed to either petroleum diesel PM extracts (D2 or SRM 1975). Representative data for IL-8 and IL-6 release are shown in Fig. (2A and $\mathbf{2 B}$ ), respectively. Though the magnitude of the slopes differed between experiments, the average slope for the IL-8 response for biodiesel (SEE and SME = 4.97) was more than the average slope for SRM 1975 (-0.675) and approximately 2.5 times greater than the Petroleum Diesel $(\mathrm{D} 2=2.03)$ run in the same engine as the biodiesel fuel (Table 2). Similarly, though the average rate of change was less for the IL-6 response compared to the IL-8 response (2.38 vs. 4.97), biodiesel as a group had an average slope for the IL-6 response (2.38) more than 5 times greater than the Petroleum Diesel (D2 $=0.465)$ extract (Table 3). The slope for SRM 1975 was 


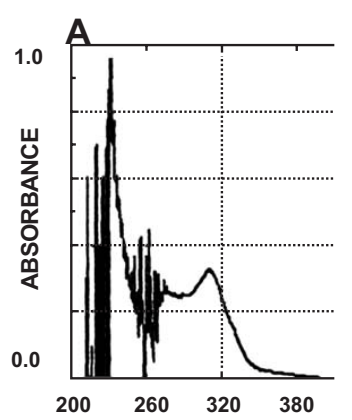

B
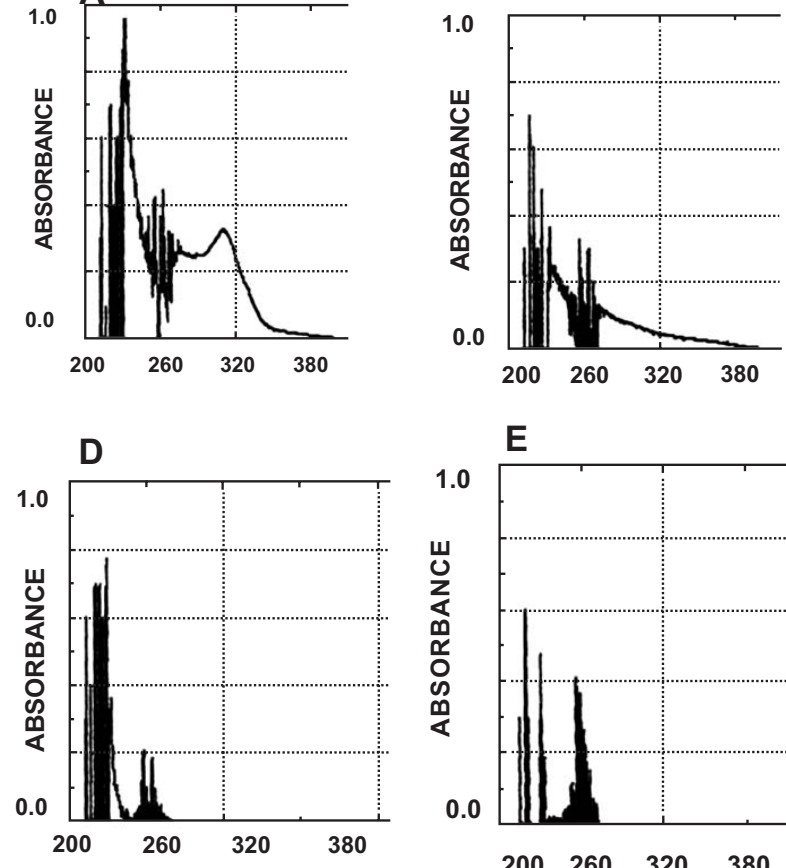

E

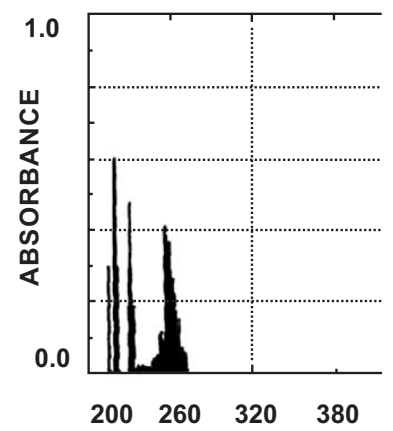

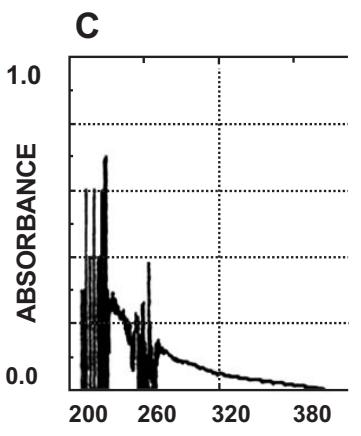

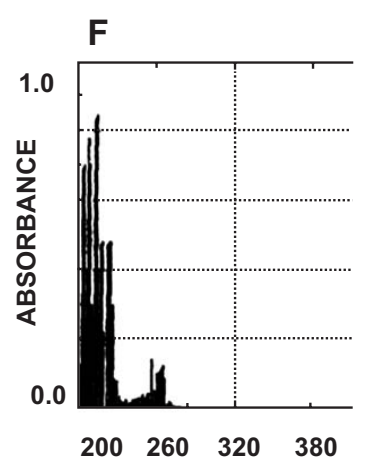

Fig. (1). Representative UV/VIS spectroscopy that verified that organics extracted into DCM were in the aqueous preparation. Representative scans are provided from one experiment for the $40 \mu \mathrm{g}$ PM eq/ml dose of (A) soy ethyl ester (SEE) in KGM and $0.2 \%$ DMSO, (B) soy methyl ester (SME) in KGM and 0.2\% DMSO, (C) petroleum diesel D2 in KGM and 0.2\% DMSO, (D) solvent blank in KGM and 0.2\% DMSO, (E) $50 \mu \mathrm{g}$ PM eq/ml SRM 1975 in KGM and 0.2\% DMSO, and (F) KGM and 0.2\% DMSO alone.
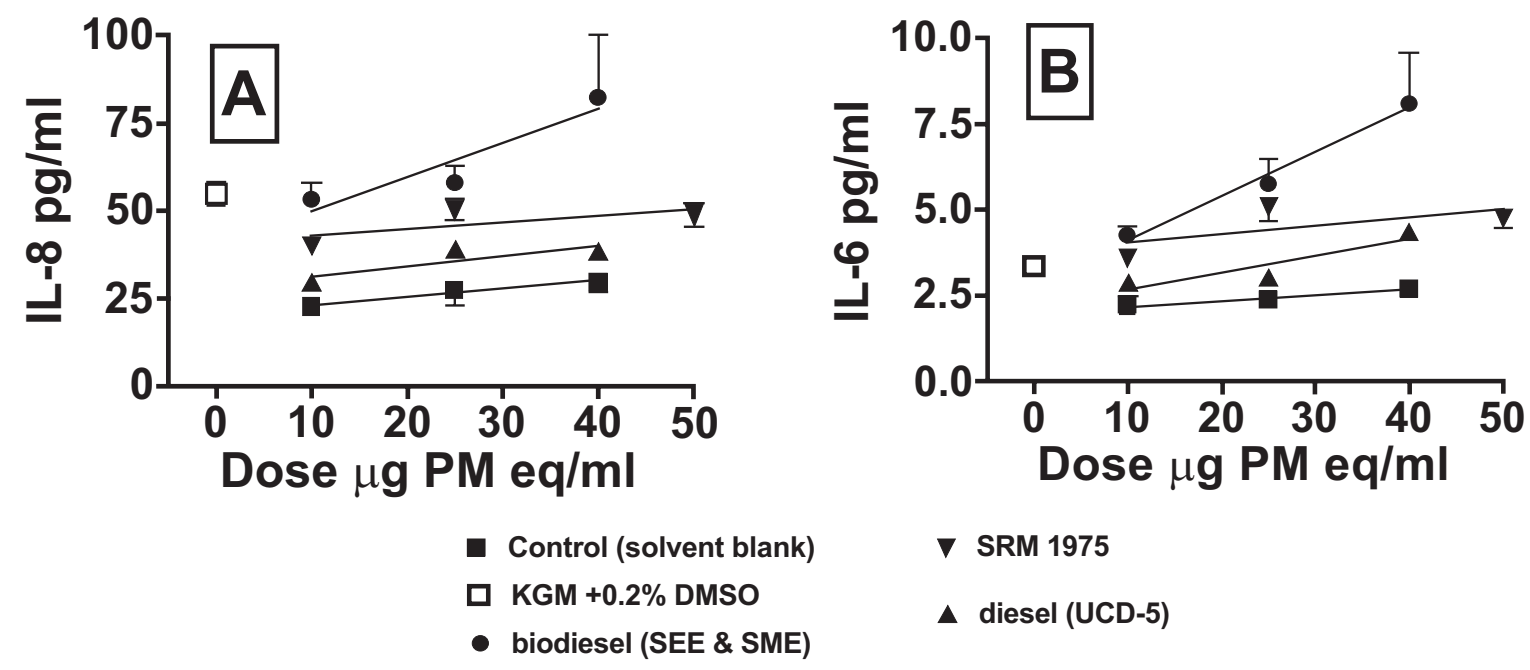

Fig. (2). The effect of diesel and biodiesel extracts exposure on (A) IL-8 and (B) IL-6 release from BEAS-2B from one experiment out of three independent experiments. Soy ethyl ester (SEE) and soy methyl ester (SME) extracts were combined as biodiesel. Each replicate is plotted for each exposure dose. The solid line represents the linear regression of the mean and the dotted lines mark the boundary of the $95 \%$ confidence interval for the regression line.

comparable to the solvent blank (0.039 vs. 0.029) in this exposure concentration range. Subsequent analysis further divided the biodiesel exposure group into SEE and SME in order to detect potency differences between biodiesel fuel types (i.e. soy esters). In experiments 1 and 2 the SEE extracts were more potent than the SME extracts, a finding consistent for both IL-8 and IL-6 responses. However, in Experiment 2 the SME extract showed a greater potency compared to the SEE extracts. Increased IL-6 and IL-8 release was induced by SRM 1975 exposure concentrations of 100-1845 $\mu \mathrm{g}$ PM eq/ml (data not shown).
The Kruskal-Wallis (one-way ANOVA) non-parametric test of the IL-8 responses by exposure category for each experiment indicated that Experiments 1 and 3 had medians that varied significantly at the $\mathrm{p}=0.05$ level (Table 2). Thus, for these two experiments, a Dunn's multiple comparison test, also called a post-test, was necessary to determine which groups had significantly different medians. The posttest revealed that Experiments 1 and 3 had statistically significant differences in IL-8 medians between control group and biodiesel and in Experiment 3, there was a statistically significant difference in IL-8 medians between the diesel 
Table 2. Summary Table of Slopes for the IL-8 Response Across Experiments by Test Material. The Unit of Change is Expressed as pg of Protein/ $\mu$ g PM eq. Statistical Analyses Performed by Kruskal-Wallis One Way ANOVA with Dunn's Multiple Comparison Test if ANOVA Reached Statistical Significance

\begin{tabular}{|c|c|c|c|c|}
\hline Test Material & Exp 1 & Exp 2 & Exp 3 & Average Slope for IL-8 \\
\hline \hline Solvent blank (vehicle) & -0.021 & -2.31 & 0.231 & -0.701 \\
\hline SRM 1975 & & -1.54 & 0.191 & -0.675 \\
\hline Petroleum Diesel (D2) & -0.100 & 5.9 & 0.291 & 2.03 \\
\hline Biodiesel (SEE \& SME) & $0.516^{*}$ & 13.4 & $0.972^{* *,+}$ & 1.67 \\
\hline SEE & 0.525 & 12.7 & -0.416 & 4.97 \\
\hline SME & 0.490 & 20.8 & 6.97 \\
\hline
\end{tabular}

Statistical significant difference at $* \mathrm{p}<0.05$ and $* * \mathrm{p}<0.01$ from vehicle, and statistical significant difference at ${ }^{+} \mathrm{p}<0.05$ from petroleum diesel are indicated.

Table 3. Summary Table of Slopes for the IL-6 Response Across Experiments by Test Material. The Unit of Change is Expressed as pg of Protein/ $\mu$ g PM eq. Statistical Analyses Performed by Kruskal-Wallis One Way Anova with Dunn's Multiple Comparison Test if ANOVA Reached Statistical Significance

\begin{tabular}{|c|c|c|c|c|}
\hline Test Material & Exp 1 & Exp 2 & Exp 3 & Average Slope for IL-8 \\
\hline \hline Solvent blank (vehicle) & 0.043 & 0.028 & 0.017 & 0.029 \\
\hline SRM 1975 & & 0.053 & 0.025 & 0.039 \\
\hline Petroleum Diesel (D2) & $0.000^{* *}$ & $1.35^{*}$ & $0.049^{* *}$ & 0.465 \\
\hline Biodiesel (SEE \& SME) & $0.351^{* * *}$ & $6.65^{* *}$ & $0.128^{* * *}$ & 2.38 \\
\hline SEE & 0.401 & 6.01 & 0.203 & 2.20 \\
\hline SME & 0.211 & 8.13 & -0.020 & 2.77 \\
\hline
\end{tabular}

Statistical significant difference at $* \mathrm{p}<0.05, * * \mathrm{p}<0.01$, and $* * * \mathrm{p}<0.001$ from vehicle are indicated.

group and the biodiesel group (Table 2). For the IL-6 cytokine responses, in all 3 experiments, medians for the IL-6 response by exposure category varied significantly at the $\mathrm{p}=0.05$ level (Table 3). The post-test revealed statistically significant differences in IL-6 medians between the control group and the diesel group and the control group and the biodiesel group but not between the diesel and biodiesel groups.

The Mann-Whitney test showed no statistically significant differences at the $\mathrm{p}=0.05$ level in the IL- 8 or IL- 6 medians between the solvent blank and the tunnel background sample (data not shown).

\section{DISCUSSION}

This study was conducted to investigate the in vitro effects of biodiesel SOF relative to two diesel SOF samples. While it is widely accepted that diesel emissions demonstrate biological and health effects, it is not fully understood which components are responsible [26]. The soluble organic fraction of diesel has been shown to elicit a pro-inflammatory response in human airway epithelial cells [27]. The transformed epithelial cell line, BEAS-2B, was a useful model to conduct a dose-response study for a vehicle emission product from a renewable fuel source not previously tested because these cells have demonstrated consistent pro-inflammatory mediator release upon exposure to diesel SOF [28]. The dose-response experiment can quickly establish a working range for future studies especially when working with a compound to which no acute biological response as been previously determined. In this study, we tested the SOF extracted from two different soy esters, commonly referred to as biodiesel (i.e. soy ethyl ester and soy methyl ester), the SOF from diesel PM emitted from the same test engine as the biodiesel PM, and a standardized diesel SOF commercially available (i.e. SRM 1975). The SRM 2975, from which the SRM 1975 originated, is a relatively low organic content diesel PM ( 2-3\% DCM extractable mass) [17].

The results of this research indicated that organic chromophores were detected in aqueous preparations of biodiesel PM extracts. Because biodiesel PM is not well studied in terms of chemical composition, it is unclear whether the extraction and the solvent exchange step (i.e., DCM to DMSO), which has been used extensively in petroleum diesel research, may be optimal for use with the biodiesel SOF. Further investigation into the chemical composition of biodiesel PM from a variety of fuels and engine operating conditions would assist in optimizing extraction methodology. The exposure of cultured airway epithelial cells to the selected doses of biodiesel SOF was not cytotoxic. Some com- 
ponent(s) in the aqueous preparations was/were either directly or indirectly responsible for the activation of proinflammatory cytokines. Compounds present in solution that are responsible for the chemokine/cytokine response may be non-aromatic/non-UV absorbing, and therefore, not detected by UV/VIS spectroscopy. Exposure to biodiesel SOF appeared to be a more potent inflammatory stimulant in BEAS2B compared to the SOF from two diesel PM samples. Biodiesel SOF elicited an increased cytokine release from BEAS-2B cells at a dose of approximately $40 \mu \mathrm{g}$ PM eq $/ \mathrm{ml}$ while exposures to petroleum diesel SOF required concentrations $>100 \mu \mathrm{g}$ PM eq/ml to induce increased cytokine release. The data are too preliminary to make any conclusion that one type of soy ester is more potent than another.

The chemical component(s) responsible for the increased potency of the biodiesel exhaust PM is not clear. The PAH analyses of the biodiesel extracts suggest little PAH content, consistent with a lack of absorbance. In general, biodiesel emissions have been shown to contain less benzene and PAHs compared to petroleum diesel emissions (as well as PM and CO) $[6,10,11]$ but with some exceptions dependent on engine type [29]. However, the PAH concentrations of biodiesel and petroleum diesel used for the cell exposures were small as PAHs were not detected in either combustion extract by GC-MS analysis based on the amount of material available. In some engines, alkene emissions are greater with biodiesel fuel relative to petroleum diesel combustion [29] raising speculation as to the participation of this chemical class in the induction of cell responses.

Comparing the cytokine response on " $\mu \mathrm{g}$ PM eq/ml" does not provide a clear idea of the actual relative potencies of the organics extracted from biodiesel PM compared to the diesel PM nor does it express the potency in terms of engine work (e.g. brake-horse power hour). Ideally, we would compare health effects response between extracts using a more meaningful unit. Kado and colleagues [30] calculated the mutagen emission rate (Rev/bhp-hr) in their studies with biodiesel SOF using PM emission rate and mutagenic potency [15, 30]. If considering the impact of SOF on a biological system, reporting the $\mathrm{PM}$ emissions either as $\mathrm{g} / \mathrm{mi}$ or $\mathrm{g} / \mathrm{bhp}-\mathrm{hr}$, the mass of extractable organics or filter extraction efficiencies, and the slope of the dose-response for the health endpoint becomes eventually necessary in the risk assessment of PM emissions. It would then be possible to tie the inflammatory response to the particulate matter emitted per mile or by brake-horse power hour and report the potential real-world exposure to inflammatory compounds as "inflammatory response/bhp-hr".

Consistent with other studies [6, 9], Durbin and colleagues demonstrated that biodiesel PM contains a higher percentage of SOF compared to the petroleum diesel PM [29]. Couple this finding to their observation that biodiesel emissions are in the ultrafine PM region and there is a motive for more health effects research. The few cytotoxicity studies on biodiesel SOF have been equivocal [31] but mutagenicity studies demonstrated less mutagenic potency for biodiesel compared to petroleum diesel $[15,32]$. Biodiesel is the first renewable diesel fuel to show signs of becoming a commercially accepted part of our nation's energy infrastructure. However, there is no published toxicological evidence that shows biodiesel combustion products reduce or elimi- nate the inflammatory potential of vehicle emissions. This pilot study, while limited in scope, offers new data on the emissions performance of biodiesel, from a public health perspective, not previously published. Currently there is no abundant supply of biodiesel PM that exists which can be readily accessed by health effects researchers for further investigation unlike standard reference material for diesel PM provided by NIST.

By examining the biological responses of the different fractions of both diesel PM extracts and biodiesel PM extracts it may be possible to identify the emission source components responsible for biological effects, in much the same way bioassay-directed chemical analysis has been used in other environmental research [30, 33-36], with possible use of the empirical data in predictive modeling. Incorporating testing of biodiesel emissions may assist in identifying the similarities and differences in the health responses (e.g. mutagencity, lung toxicity, etc.) relative to composition [34]. This information would be valuable to vehicle manufacturers so they can make improvements to fuel injector systems or exhaust gas post-treatment technologies [27]. Additionally, understanding whether biodiesel emissions could potentially contribute to a component of air pollution that may induce or exacerbate asthma symptoms or other illnesses associated with ambient PM exposure would be important to the fledgling biodiesel industry and the transportation industry.

\section{DISCLAIMER}

This report has been reviewed by the National Health and Environmental Effects Research Laboratory, United States Environmental Protection Agency and approved for publication. Approval does not signify that the contents necessarily reflect the views and policies of the Agency nor does mention of trade names or commercial products constitute endorsement or recommendation for use.

\section{ACKNOWLEDGMENTS}

Support for this work was provided, in part, by the NHEERL/DESE Cooperative Training in Environmental Sciences Research, EPA CT826513, and US EPA internal funding. We also acknowledge support from United States Department of Energy and the Montana State Department of Environmental Quality.

\section{ABBREVIATIONS}

$\mathrm{KOH}=$ Potassium Hydroxide
MMGY $=$ Million Gallons/year
$\mathrm{NBB}=$ National Biodiesel Board
$\mathrm{THC}=$ Total Hydrocarbon
PAH $=$ Polycyclic Aromatic Hydrocarbon
$\mathrm{RME}=$ Rapeseed Methyl Ester
$\mathrm{D} 2$
$\mathrm{ED} 50$ Phillips Diesel
$\mathrm{B} 2$
$\mathrm{~B} 20$ Median Effective Dose
$\mathrm{NIST}=2 \%$ Biodiesel
$\mathrm{SME}=$ Soybean Methyl Ester




\section{REFERENCES}

[1] Clean Air Act Amendments of 1990. 42 U.S.C 7401-7671q. Subchapter I-program \& Activities, 1990; pp. 101-549.

[2] U.S. Environmental Protection Agency. National Air Pollutant Emission Trends, 1900-1998, U.S. EPA Office of Transportation and Air Quality Planning and Standards, (U.S. EPA No. EPA454/R-00-002). Research Triangle Park: NC 2000.

[3] Bünger J, Krahl J, Baum K, et al. Cytotoxic and mutagenic effects, particle size and concentration analysis of diesel engine emissions using biodiesel and petrol diesel as fuel. Arch Toxicol 2000; 74(8): 490-498.

[4] Chen YC, Wu CH. Emissions of submicron particles from a direct injection diesel engine by using biodiesel. J Environ Sci Health A Tox Hazard Subst Environ Eng 2002; 37(5): 829-843.

[5] Durbin TD, Collins JR, Galdamez H, et al. Evaluation of the effects of biodiesel fuel on emisssions form heavy-duty non-road vehicles, in center for environmental research and technology, University of California; Riverside: CA 2000.

[6] Graboski MS, McCormick RL, Alleman TL, Herrin AM. The effect of biodiesel composition on engine emissions from a DDC series 60 diesel engine. Colorado Institute for Fuels and Engine Research, Colorado School of Mines; Golden, Colorado: 2003.

[7] Krahl J, Baum K, Hackbarth U, et al. Gaseous compounds, ozone precursors, particle number and particle size distruibutions, and mutagenic effects due to biodiesel. Trans ASAE 1999; 44(2): 179191.

[8] McCormick RL, Graboski MS, Alleman TL, Herring AM, Tyson KS. Impact of biodiesel source material and chemical structure on emissions of criteria pollutants from a heavy-duty engine. Environ Sci Technol 2001; 35(9): 1742-1747.

[9] Sharp C. Characterization of biodiesel exhaust emissions for EPA 211(b). Southwest Research Institute: San Antonio; TX 1998; p. 21.

[10] Sharp C, Howell S, Jobe J. The effect of biodiesel fuels on transient emissions from modern diesel engines, Part II Unregulated Emissions and Chemical Characterization. Technical Paper 2000-011968. SAE; Warrendale: PA 2000.

[11] McDonald J, Spears MW. Biodiesel: effects on exhaust constituents. In: Martini N, Schell J, Eds. Plant oils as fuels-Present state of science and future developments. Springer; Berlin: 1997; pp. 141160.

[12] Graboski MS, McCormick RL. Combustion of fat and vegetable oil derived fuels in diesel engines. Prog Energy Combust Sci 1998; 24: 125-164.

[13] Holgate ST, Sandström T, Frew AJ, et al. Health effects of acute exposure to air pollution. Part I: Healthy and asthmatic subjects exposed to diesel exhaust. Res Rep Health Eff Inst 2003; 112: 1-67.

[14] McKinnon KP, Noah T, Madden MC, Devlin RB. In vitro ozone exposure increases release of arachidonic acid products from a human bronchial epithelial cell line. Toxicol Appl Pharmacol 1993; 118(2): 215-223.

[15] Kado NY, Kuzmicky PA. Bioassay analyses of particulate matter from a diesel bus engine using various biodiesel feedstock fuels, in final report for national renewable energy laboratory (NREL/SR510-31463). Department of Environmental Toxicology, University of California; Davis: CA 2003; p. 25.

[16] Petersen BA, Chuang CC. Methodology of fractionation and partition of diesel exhaust particulate samples. In: Lewtas J, Ed. Toxicological effects of emissions from diesel engines, Elsevier Science Publishing Co, Inc.; 1982; 51-67.

[17] National Institute of Standards \& Technology, Certificate of Analysis for Standard Reference Material 1975. [Online] 2000: Gaithersburg, MD. Available from: https://www-s.nist.gov/srmors/ view_detail.cfm?srm=1975

[18] National Institute of Standards \& Technology, Certificate of Analysis for Standard Reference Material 2975. [Online] 2000: Gaithersburg, MD.Available from: https://www-s.nist.gov/srmors/ view_detail.cfm?srm=2975
[19] Li N, Wang M, Oberley TD, Sempf JM, Nel AE. Comparison of the pro-oxidative and proinflammatory effects of organic diesel exhaust particle chemicals in bronchial epithelial cells and macrophages. J Immunol 2002; 169(8): 4531-4541.

[20] Tsien A, Diaz-Sanchez D, Ma J, Saxon A. The organic component of diesel exhaust particles and phenanthrene, a major polyaromatic hydrocarbon constituent, enhances IgE production by IgE-secreting EBV-transformed human B cells in vitro. Toxicol Appl Pharmacol 1997; 142(2): 256-263.

[21] Lewtas J, Bradow RL, Jungers RH, Harris BD, Zweidinger RB, Cushing KM. Mutatgenic and Carcinogenic potency of extracts of diesel and related environmental emissions: study design, sample generation, collection, and preparation. Environ Int 1981; 5(4-6): 383-387.

[22] Molinelli AR, Santacana G, Madden MC, Jiménez BD. Cytotoxicity and metal content of organic solvent extracts from airborne particulate matter in Puerto Rico. Environ Res 2006; 102(3): 314-325.

[23] Gerlier D, Thomasset N. Use of MTT colorimetric assay to measure cell activation. J Immunol Methods 1986; 94(1-2): 57-63.

[24] Pleil JD, Vette AF, Rappaport SM. Assaying particle-bound polycyclic aromatic hydrocarbons from archived PM2.5 filters. J Chromatogr A 2004; 1033(1): 9-17.

[25] Pagano M, Gauvreau K. Principles of Biostatistics. $2^{\text {nd }}$ ed. Duxbury; Pacific Grove: CA 2000.

[26] U.S. Environmental Protection Agency. Health Assessment Document for Diesel Engine Exhaust. (U.S. EPA Report EPA/600/890/057F). Washington, DC. Author, 2002.

[27] Bonvallot V, Baeza-Squiban A, Baulig A, et al. Organic compounds from diesel exhaust particles elicit a proinflammatory response in human airway epithelial cells and induce cytochrome p450 1A1 expression. Am J Respir Cell Mol Biol 2001; 25(4): 515521.

[28] Takizawa H, Ohtoshi T, Kawasaki S, et al. Diesel exhaust particles activate human bronchial epithelial cells to express inflammatory mediators in the airways: a review. Respirology 2000; 5(2): 197203.

[29] Durbin TD, Collins J, Norbeck J, Smith M. Evaluation of the effects of alternative diesel fuel formulations on exhaust emission rates and reactitivity. Final Report for South Coast Air Quality Management District Technology Advancement Office (98102). Center for Environmental Research and Technology, University of California; Riverside: CA 1999.

[30] Kado NY, Okamoto RA, Kuzmicky PA. Chemical and bioassay analyses of diesel and biodiesel particulate matter: pilot study. In: Final Report for the Montana State Department of Environmental Quality and U.S. Department of Energy. Department of Environmental Toxicology, University of California; Davis: CA 1996.

[31] Finch GL, Hobbs CH, Blair LF, et al. Effects of subchronic inhalation exposure of rats to emissions from a diesel engine burning soybean oil-derived biodiesel fuel. Inhal Toxicol 2002; 14(10): 1017-1048.

[32] Bünger J, Krahl J, Franke HU, Munack A, Hallier E. Mutagenic and cytotoxic effects of exhaust particulate matter of biodiesel compared to fossil diesel fuel. Mutat Res 1998; 415(1-2): 13-23.

[33] Oh SM, Chung KH. Identification of mammalian cell genotoxins in respirable diesel exhaust particles by bioassay-directed chemical analysis. Toxicol Lett 2006; 161(3): 226-235.

[34] DeMarini DM, Brooks LR, Warren SH, Kobayashi T, Gilmour MI, Singh P. Bioassay-directed fractionation and Salmonella mutagenicity of automobile and forklift diesel exhaust particles. Environ Health Perspect 2004; 112(8): 814-819.

[35] Schuetzle D, Lewtas J. Bioassay-directed chemical analysis in environmental research. Anal Chem 1986; 58(11): 1060A-1075A.

[36] Seagrave J, McDonald JD, Gigliotti AP, et al. Mutagenicity and in vivo toxicity of combined particulate and semivolatile organic fractions of gasoline and diesel engine emissions. Toxicol Sci 2002; 70(2): 212-226. 